\title{
Phenobarbitone, phenytoin, carbamazepine, or sodium valproate for newly diagnosed adult epilepsy: a randomised comparative monotherapy trial
}

A J Heller, P Chesterman, R D C Elwes, P Crawford, D Chadwick, A L Johnson, E H Reynolds

\begin{abstract}
Recent studies have shown that most newly diagnosed epileptic patients can be satisfactorily treated with a single antiepileptic drug. We therefore undertook a prospective randomised pragmatic trial of the comparative efficacy and toxicity of four major antiepileptic drugs, utilised as monotherapy in newly diagnosed epileptic patients.
\end{abstract}

Between 1981 and 1987243 adult patients aged 16 years or over, newly referred to two district general hospitals with a minimum of two previously untreated tonic-clonic or partial with or without secondary generalised seizures were randomly allocated to treatment with phenobarbitone, phenytoin, carbamazepine, or sodium valproate. The protocol was designed to conform with standard clinical practice. Efficacy was assessed by time to first seizure after the start of treatment and time to enter one year remission. The overall outcome with all of the four drugs was good with $27 \%$ remaining seizure free and $75 \%$ entering one year of remission by three years of follow up. No significant differences between the four drugs were found for either measure of efficacy at one, two, or three years of follow up. The overall incidence of unacceptable side effects, necessitating withdrawal of the randomised drug, was $10 \%$. For the individual drugs phenobarbitone (22\%) was more likely to be withdrawn than phenytoin $(3 \%)$, carbamazepine $(11 \%)$, and sodium valproate (5\%). In patients with newly diagnosed tonic-clonic or partial with or without secondary generalised seizures, the choice of drug will be more influenced by considerations of toxicity and costs.

(F Neurol Neurosurg Psychiatry 1995;58:44-50)

Keywords: antiepileptic drugs; epilepsy; monotherapy trial

Throughout most of this century there has been a widespread tendency to treat epileptic patients with polytherapy. After the advent of monitoring of antiepileptic drugs in blood, our own and other studies in the 1970s showed that there was much unnecessary polytherapy $^{1}$ and that the potential for single drug treatment was much greater than was appreciated, especially in newly diagnosed patients, in whom it was associated with excellent long term prognosis..$^{2-5} \mathrm{By}$ the end of that decade it became clear that it was necessary to undertake studies of the comparative efficacy and toxicity of all the major antiepileptic drugs in newly diagnosed patients. At the time we began our study in 1981 there was no information available on the comparative efficacy of any of the major antiepileptic drugs utilised as monotherapy in newly diagnosed epileptic patients and very little information on their comparative efficacy as add on treatment in chronic epileptic patients. ${ }^{6}$ Since then there have been reports of randomised monotherapy trials in newly diagnosed patients involving the comparison of two, ${ }^{7-9}$ three, ${ }^{10}$ and four ${ }^{11}$ drugs.

We present here the results of a long term open, randomised, pragmatic study of the comparative efficacy and toxicity of four widely used antiepileptic drugs (phenobarbitone, phenytoin, carbamazepine, and sodium valproate) in previously untreated, newly diagnosed, adult epileptic patients. A similar clinical trial of the same four drugs in children will be reported separately. ${ }^{12}$

\section{Methods}

OBJECTIVE

The objective was to compare the efficacy and toxicity of phenobarbitone, phenytoin, carbamazepine, and sodium valproate in a randomised, prospective, pragmatic, long term trial in newly diagnosed adult epileptic patients.

\section{CENTRES}

Recruitment commenced in the neurological outpatient department of King's College Hospital, London in February 1981, and of Walton Hospital, Liverpool in June 1982. Recruitment ceased in July 1987.

\section{PATIENTS}

Inclusion criteria were: (a) age 16 years or over; (b) a minimum of two or more tonicclonic seizures or partial seizures with or without secondary generalisation in the preceding year; (c) no previous antiepileptic drug treatment; (d) agreement to randomisation to one of the four study drugs.

Exclusion criteria were: (a) other seizure types, myoclonus, or pseudoseizures; (b) drug 
or alcohol induced seizures; (c) clinical or other evidence of progressive neurological disease-for example, tumour.

\section{BASELINE ASSESSMENTS}

A detailed history was obtained from patients and relatives or witnesses and all patients underwent general and neurological examination, haematological (Coulter counter), and biochemical (Technicon RA1000 analyser) analysis, and a standard EEG while awake. Computed tomography of the head was undertaken in patients with clinical or EEG evidence of a focal (partial) seizure disorder.

\section{STRATIFICATION}

Patients were stratified by centre (London or Liverpool), seizure type (tonic-clonic or partial with or without secondary generalisation), and mental or neurological handicap (absent or present). The seizure type was based on the clinical information available at the time of randomisation. A handicap was defined by a full scale IQ $<70$ or the presence of clinical signs of a brain lesion (for example, field defect, hemiparesis).

\section{RANDOMISATION}

Patients were randomised to one of the four antiepileptic drugs using prepared batches of serially numbered sealed envelopes with allocations balanced over blocks of 16 (no handicap strata) or eight (handicap strata). Randomisation was coordinated separately within the two centres, and the identity of allocated treatments was not masked.

DOSING, PLASMA MONITORING, SEIZURE RECORDING, AND SIDE EFFECTS

Patients were started on a small dose of the allocated drug given twice daily (table 1) and were seen at one month and thereafter at least three monthly. Plasma drug concentrations were monitored at each clinic visit, but the dose of the drug was increased only if seizures recurred, despite good compliance. Table 1 shows the incremental doses for each drug. Seizure type and frequency were recorded by the patient and/or relative on a seizure calendar. In the event of further seizures the dose of the drug was increased until seizures ceased or until the plasma concentration of the drug was in the top half of the optimum range for that drug (table 1). If seizures persisted, the patient was considered to have failed on monotherapy with the randomised drug and either an alternative drug of the physician's choosing was prescribed or a second drug, usually carbamazepine, was added. If at any stage during follow up an unacceptable side

Table 1 Starting and incremental doses of antiepileptic drugs and plasma concentration ranges

\begin{tabular}{lccc}
\hline Drug & Starting dose (mg/day) & Incremental dose (mg) & $\begin{array}{l}\text { Optimum } \\
\text { range }(\mathrm{mcg} / \mathrm{ml})\end{array}$ \\
\hline Phenobarbitone & 60 & 30 & $20-40$ \\
Phenytoin & 200 & 50 & $10-20$ \\
Carbamazepine & 400 & 200 & $4-11$ \\
Sodium valproate & 400 & 200 & $50-100$ \\
\hline
\end{tabular}

effect occurred of an idiosyncratic, hypersensitive, or dose related kind, the randomised drug was withdrawn and an alternative drug of the physician's choosing was substituted.

\section{FOLLOW UP}

Patients were followed up to 31 March 1988, or to loss to follow up or death. Patients who attained two years of freedom from seizures were eligible for consideration for withdrawal of their antiepileptic drug treatment.

\section{STATISTICS}

Comparative efficacy of the drugs was assessed by analysis of $(a)$ time to first seizure recurrence after the start of treatment and (b) time to achieve one year of remission from all seizures.

Analysis was based on the policy of intention to treat. ${ }^{13}$

The intervals from randomisation to the first seizure postrandomisation (or the last date of follow up in patients who remained seizure free) and from randomisation to the date of achieving one year of remission from all seizures (or the last date of follow up in patients not achieving one year of remission), were calculated to the nearest week and summarised by actuarial life table techniques. ${ }^{13}$ Treatment effects, both unadjusted and adjusted for design features (centre, seizure type, and handicap) as well as for important prognostic variables (see table 6), have been estimated with the Cox proportional hazards regression model and are summarised as relative risks with $95 \%$ confidence intervals. As there is no placebo control or standard treatment group, the treatment effects in the Cox model have been coded as deviations from the average and the logarithms of their relative risks are constrained to sum to zero. ${ }^{14}$

The design of this clinical trial envisaged a total of 60 patients allocated to each drug with an average follow up period of four years. Assuming by this stage that about $25 \%$ of patients were seizure free and $80 \%$ had achieved one year of remission, the power of the trial would exceed $80 \%$ (using the log rank statistic at $\mathrm{p}=0.05$ (two tailed)) to detect improvements to $50 \%$ seizure free, or $95 \%$ achieving one year of remission, when comparing two drugs. ${ }^{15}$

\section{Results}

A total of 243 patients were randomised to the four drugs. Table 2 shows that there were no important differences between the four drug groups for age at randomisation, sex, seizure type, presence of mental handicap, neurological lesion or psychiatric history, time between first seizure and randomisation, and the total number of seizures before randomisation.

The median duration of follow up was 30 (range one to 91) months. Forty seven patients were followed up for less than one year. This included 25 patients with protocol violations, among whom 11 patients defaulted within one month of randomisation. Six patients were randomised in error, four in 
Table 2 Patient characteristics in four drug groups

\begin{tabular}{|c|c|c|c|c|c|}
\hline & $P B$ & $P H Y$ & $C B Z$ & $S V$ & Total \\
\hline Total & 58 & 63 & 61 & 61 & 243 \\
\hline $\begin{array}{l}\text { Centre: } \\
\text { London } \\
\text { Liverpool }\end{array}$ & $\begin{array}{l}30(52) \\
28(48)\end{array}$ & $\begin{array}{l}33(52) \\
30(48)\end{array}$ & $\begin{array}{l}34(56) \\
27(44)\end{array}$ & $\begin{array}{l}33(54) \\
28(46)\end{array}$ & $\begin{array}{l}130(53) \\
113(47)\end{array}$ \\
\hline $\begin{array}{l}\text { Age at randomisation (y): } \\
\text { Median (25th, 75th centile) }\end{array}$ & $30(22,43)$ & $32(20,39)$ & $23(19,34)$ & $29(19,40)$ & $29(19,40)$ \\
\hline $\begin{array}{l}\text { Sex }(\text { No }(\%)): \\
\text { Men } \\
\text { Women }\end{array}$ & $\begin{array}{l}25(43) \\
33(57)\end{array}$ & $\begin{array}{l}34(54) \\
29(46)\end{array}$ & $\begin{array}{l}30(49) \\
31(51)\end{array}$ & $\begin{array}{l}28(46) \\
33(54)\end{array}$ & $\begin{array}{l}117(48) \\
126(52)\end{array}$ \\
\hline $\begin{array}{l}\text { Seizure type (No (\%)): } \\
\text { TC } \\
\text { P } \pm \text { TC } \\
\text { Mental handicap (No (\%)) } \\
\text { Neurological lesion (No (\%)) } \\
\text { Psychiatric history (No (\%)) }\end{array}$ & $\begin{array}{c}33(57) \\
25(43) \\
6(10) \\
4(7) \\
5(9)\end{array}$ & $\begin{array}{c}35(56) \\
28(44) \\
9(14) \\
11(17) \\
4(6)\end{array}$ & $\begin{array}{c}37(61) \\
24(39) \\
9(15) \\
8(13) \\
2(3)\end{array}$ & $\begin{aligned} 36(59) \\
25(41) \\
7(11) \\
8(14) \\
5(8)\end{aligned}$ & $\begin{array}{r}141(58) \\
102(42) \\
31(13) \\
31(13) \\
16(7)\end{array}$ \\
\hline $\begin{array}{l}\text { Period between } 1 \text { st seizure and randomisation: } \\
\text { Median (weeks) (25th, } 75 \text { th centile) }\end{array}$ & $53(19,157)$ & $58(18,217)$ & $81(29,251)$ & $41(20,185)$ & $52(22,199)$ \\
\hline $\begin{array}{l}\text { Estimated total number of seizures prerandomisa } \\
\text { Median (25th, 75th centile) }\end{array}$ & ion: $\quad 4(2,25)$ & $5(3,55)$ & $4(2,12)$ & $4(2,10)$ & $4(2,25)$ \\
\hline
\end{tabular}

whom it later emerged had pseudoseizures and two alcohol induced seizures. Three patients died during the course of the study, $1 \cdot 5,3 \cdot 3$, and four years after randomisation. One was a sudden unexplained death, presumed asphyxia, one was due to drowning, and one was due to a subarachnoid haemorrhage.

Table 3 Side effects resulting in drug withdrawal

\begin{tabular}{lllllc}
\hline & $P B$ & $P H Y$ & $C B Z$ & $S V$ & Total \\
\hline Drowsiness & 4 & 0 & 3 & 0 & 7 \\
Lethargy & 4 & 0 & 0 & 0 & 4 \\
Rash & 1 & 0 & 2 & 0 & 3 \\
Dizziness & 2 & 0 & 0 & 2 & 4 \\
Headache & 0 & 0 & 1 & 0 & 1 \\
Nightmares & 1 & 0 & 0 & 0 & 1 \\
Nausea and vomiting & 1 & 0 & 0 & 0 & 1 \\
Abnormal LFTs & 0 & 0 & 0 & 1 & 1 \\
Myalgia & 0 & 1 & 0 & 0 & 1 \\
Irritability & 0 & 1 & 0 & 0 & 1 \\
Depression & 0 & 0 & 1 & 0 & 1 \\
Total & $13(22 \%)$ & $2(3 \%)$ & $7(11 \%)$ & $3(5 \%)$ & $25(10 \%)$ \\
\hline
\end{tabular}

LFT = liver function tests. Other abbreviations as table 2 .

Table 4 Actuarial percentages seizure free by selected intervals after randomisation

\begin{tabular}{llllllll}
\hline & \multirow{2}{*}{$\begin{array}{l}\text { Randomised } \\
\text { No }\end{array}$} & $\begin{array}{l}\text { Secizure } \\
\text { recurrence }\end{array}$ & $\begin{array}{l}\text { Seizure } \\
\text { free }\end{array}$ & \multicolumn{5}{l}{ Actuarial \% seizure free } \\
\cline { 5 - 8 } & No & & No & 6 months & 1 year & 2 years & 3 years \\
\hline Phenobarbitone & 58 & 35 & 23 & 49 & 39 & 33 & 33 \\
Phenytoin & 63 & 41 & 22 & 51 & 40 & 32 & 28 \\
Carbamazepine & 61 & 40 & 21 & 56 & 48 & 24 & 21 \\
Sodium valproate & 61 & 38 & 23 & 50 & 42 & 32 & 28 \\
Total & 243 & 154 & 89 & 51 & 42 & 30 & 27 \\
\hline
\end{tabular}

Table 5 Actuarial percentages achieving one year remission by selected intervals after randomisation

\begin{tabular}{|c|c|c|c|c|c|c|}
\hline \multirow[b]{2}{*}{ Treatment group } & \multirow{2}{*}{$\begin{array}{l}\text { Randomised } \\
\text { No }\end{array}$} & \multirow{2}{*}{$\begin{array}{l}\text { Failed to } \\
\text { achieve } 1 \text { year } \\
\text { remission } \\
\text { No }\end{array}$} & \multirow{2}{*}{$\begin{array}{l}\text { Achieved } \\
1 \text { year } \\
\text { remission } \\
\text { No }\end{array}$} & \multicolumn{3}{|c|}{$\begin{array}{l}\text { Actuarial \% achieving } \\
1 \text { year remission }\end{array}$} \\
\hline & & & & 1 year & 2 years & 3 years \\
\hline Phenobarbitone & 58 & 28 & 30 & 35 & 61 & 74 \\
\hline Phenytoin & 63 & 26 & 37 & 37 & 58 & 72 \\
\hline Carbamazepine & 61 & 25 & 36 & 46 & 67 & 77 \\
\hline Sodium valproate & 61 & 25 & 36 & 35 & 61 & 74 \\
\hline Total & 243 & 104 & 139 & 39 & 61 & 75 \\
\hline
\end{tabular}

Twenty five patients (10\%) developed unacceptable side effects during the study, requiring withdrawal and substitution of an alternative drug. Over half of these (13 patients) were associated with phenobarbitone, representing $22 \%$ of patients randomised to this drug. For the other three drugs the corresponding figures were phenytoin two patients (3\%), carbamazepine seven $(11 \%)$, and sodium valproate three (5\%). Table 3 summarises the details. There was a significant difference between the proportion of patients withdrawn from the randomised drugs because of unacceptable side effects $\left(\chi^{2}\right.$ $=14.7, \mathrm{df}=3, \mathrm{p}<0.01)$. Patients randomised to phenobarbitone were more likely to have the drug withdrawn than those randomised to other treatments $\left(\chi^{2}=12 \cdot 1, \mathrm{df}=\right.$ $1, \mathrm{p}<0.001$; odds ratio $4.2 ; 95 \%$ confidence interval (95\% CI) $1 \cdot 6-10 \cdot 6)$. Patients randomised to carbamazepine were more likely to have the drug withdrawn than those randomised to phenytoin or sodium valproate, although here the proportions of withdrawals were not statistically significant $\left(\chi^{2}=3 \cdot 73, \mathrm{df}=\right.$ $1, \mathrm{p}<0.06 ; 3,1(0.8,11 \cdot 8))$.

The overall analysis of outcome for the 243 patients in this study showed that by three years of follow up 27 (95\% CI 20-33)\% were seizure free (table 4); 75 (95\% CI 69-82)\% had achieved a one year remission (table 5) and 42 (95\% CI 33-50)\% a two year remission. The four policies of treatment are compared by the percentages remaining seizure free (table 4; fig 1) or achieving a one year period of remission of all seizures (table 5; fig 2). Differences between these percentages for the four drug groups are small with between $21 \%$ and $33 \%$ seizure free by three years of follow up, and between 72 and $77 \%$ achieving one year remission by three years. Table 6 shows, for each drug group, the estimated ratio of the odds for seizure recurrence or one year remission relative to the average odds over the four drug groups combined. The odds ratios (relative risks) for each drug 
Figure 1 Actuarial percentages of patients remaining seizure free in the four drug groups.

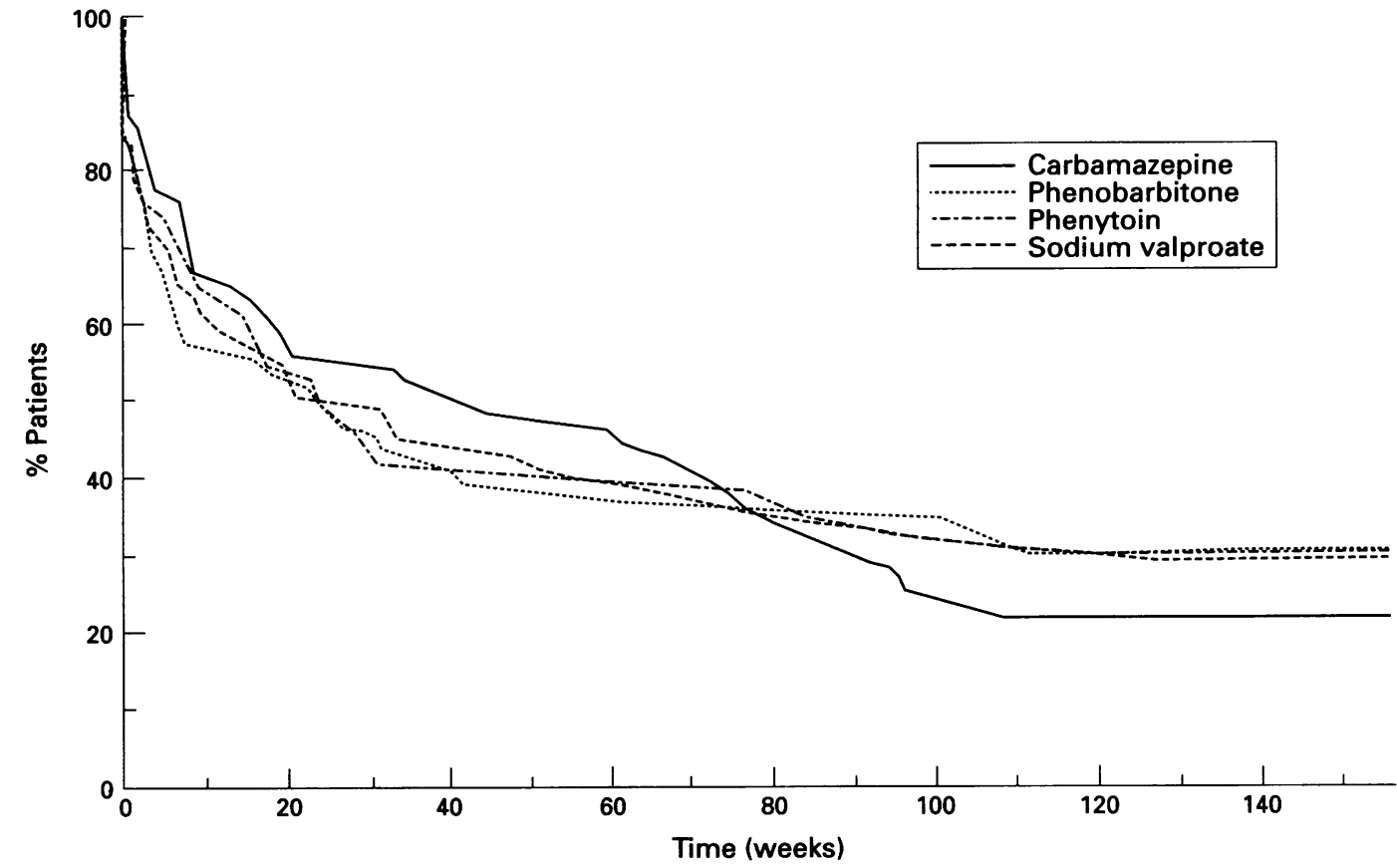

indicate only small departures from the average, although with wide confidence intervals. Table 6 also shows the likelihood ratio $\chi^{2}$ statistics comparing the four treatment groups. No significant differences at $p=0.05$ were found. The adjustment for factors considered of potential prognostic importance, summarised in table 6 , made only minor differences. The comparison of the four drugs includes an adjustment for seizure type, but we also undertook a separate test of interaction between the drugs and seizure type, which failed to show any significant influence of the two different seizure categories on the comparative efficacy (table 6). Of the 141 patients randomised to the tonic-clonic group 124 had primary generalised epilepsy and 17 had focal abnormalities on the EEG that suggested the possibility of secondary generalised tonic-clonic attacks. Switching these 17 patients from the tonic-clonic group to the partial with or without secondary generalised group made only minor changes and no sig-

nificant differences to the relative risks or drug and seizure type interaction (table 6).

At three years of follow up $76 \%$ remained on the randomised drug, $10 \%$ discontinued medication (after two years of remission), and $14 \%$ were taking an additional or alternative drug. Also, at three years the median dose (range) of each drug was: phenobarbitone 105 (90-180) $\mathrm{mg}$, phenytoin $300(200-450) \mathrm{mg}$, carbamazepine $600(400-1600) \mathrm{mg}$, and sodium valproate $800 \quad(400-2000) \mathrm{mg}$. Among patients who had failed to achieve one year of remission by three years of follow up, $20 \%$ also failed to achieve an optimum plasma concentration of the randomised drug, usually due to poor compliance. For the individual drugs the percentages were phenobarbitone $42 \%$, phenytoin $20 \%$, carbamazepine $7 \%$, and sodium valproate $7 \cdot 5 \%$. The overt and perhaps subtle side effects of phenobarbitone and phenytoin may have contributed to the higher percentage with these two older drugs.
Figure 2 Actuarial percentages of patients achieving one year remission in the four drug groups.

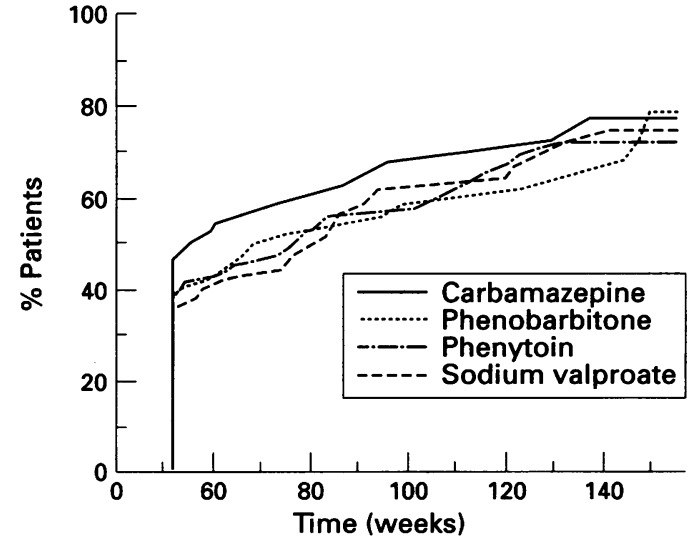

Table 6 Comparison of treatments

\begin{tabular}{|c|c|c|}
\hline & \multicolumn{2}{|c|}{ Relative risks $(95 \% C L) *$} \\
\hline & Time to 1st seizure & Time to 1 year remission \\
\hline $\begin{array}{l}\text { Phenobarbitone } \\
\text { Phenytoin } \\
\text { Carbamazepine } \\
\text { Sodium valproate } \\
\chi^{2}(p), \mathrm{df}=3 \\
\text { Tests of interaction } \\
\text { between drugs } \\
\text { and seizure type } \\
\chi^{2}(\mathrm{p}), \mathrm{df}=3\end{array}$ & $\begin{array}{l}0.93(0.69-1.24) \\
0.96(0.73-1.26) \\
1.03(0.78-1.36) \\
1.09(0.82-1.44) \\
0.53(p=0.91) \\
2.81(p=0.42)\end{array}$ & $\begin{array}{l}0.98(0.72-1.32) \\
1.09(0.81-1.45) \\
1.05(0.78-1.41) \\
0.90(0.67-1.21) \\
0.70(p=0.87)\end{array}$ \\
\hline
\end{tabular}




\section{Discussion}

We have found no significant differences in efficacy between the four randomised major antiepileptic drugs in either time to first seizure recurrence or time to achieve one year of remission from all seizures. The findings are similar for the two seizure categories (tonic-clonic or partial with or without secondary generalisation). Tables 4 and 5 and figs 1 and 2 show that at one, two, and three years of follow up the percentages of patients remaining seizure free or achieving a one year remission were similar for all four drugs. The odds ratios (relative risks) in table 6 quantify the comparative efficacies of treatment after adjusting for multiple design and prognostic variables, including seizure category, and show no significant differences between the four drugs. The confidence intervals are not sufficiently narrow to preclude $25 \%$ reductions in relative risk of seizure recurrence or $30 \%$ increases in relative risks of achieving a one year remission. In parallel with this study on adults we have conducted a similar randomised comparative monotherapy trial with the same four drugs in newly diagnosed children between the ages of 3 and 16 and with the same seizure types-that is, tonic-clonic seizures or partial seizures with or without secondary generalisation. This trial also failed to show differences in efficacy between the drugs, and had similar odds ratios to the trial with adults. ${ }^{12}$

Since we began our study in 1981, five randomised comparative monotherapy trials in adults with newly diagnosed epilepsy have been reported..$^{7-11}$ Table 7 summarises these. The drugs compared, the numbers of patients, design of the study, duration of follow up, and measures of efficacy have varied, but with minor exceptions the authors failed to show differences in efficacy between the drugs. In a double blind study Ramsay et $a l^{7}$ found no differences between phenytoin and carbamazepine in achieving "complete control" of tonic-clonic seizures or partial seizures with or without tonic-clonic seizures during the first six months of treatment. In an open study Wilder et al $^{8}$ similarly found no differences in efficacy between phenytoin and sodium valproate in the complete control of tonic-clonic, tonic, or clonic seizures between two and six months after the start of treatment. Turnbull et $a l^{9}$ employed actuarial methods of analysis, of the kind used in the present study, and found no differences in efficacy between phenytoin and sodium valproate for tonic-clonic or partial seizures treated openly for two years. Callaghan et al ${ }^{10}$ compared three drugs-namely, phenytoin, carbamazepine, and sodium valproate-and classified seizure control as excellent, good, and poor in their open study of patients with tonic-clonic and partial seizures followed up for 14 to 24 months. Again no differences in efficacy emerged, with the single exception that for tonic-clonic seizures significantly more patients on phenytoin than carbamazepine achieved excellent control compared with good control.
The largest and most influential study is that of the Veterans Administration (VA) Collaborative Group ${ }^{11}$ with which our study has some similarities and some important differences, but broadly similar conclusions. The VA group compared four drugs that included primidone, but not sodium valproate as in our study. The patients in the VA study had only partial seizures with or without secondary generalisation whereas we also included patients with tonic-clonic seizures alone. Forty two per cent of the patients in the VA group had either had antiepileptic drugs in the past $(21 \%)$ or were taking such drugs at the time of referral $(21 \%)$. The VA study was double blind and the objective was to rapidly achieve therapeutic blood concentrations, which, if failing to control seizures, were increased to toxic concentrations. Our study was open and designed to conform to standard clinical practice so that the small starting doses of the drugs were not increased if seizures did not recur and drugs were not increased beyond the optimum plasma concentration ranges (table 1 ) in the event of continuing seizures. The VA group did not utilise actuarial statistics except to analyse retention time on the four drugs, for which primidone was significantly worse, mainly due to toxicity. Comparative efficacy was assessed at sixmonthly intervals over the three year period of follow up by several measures-namely, seizure frequency per month, total number of seizures (at yearly intervals), first seizure recurrence, total seizure control after the first month of treatment (to achieve therapeutic drug concentrations), and a rating scale that incorporated seizure severity and interference with everyday life. For all these analyses, which were applied separately to partial and to secondary generalised seizures, the only significant difference to emerge was that total seizure control of partial seizures was superior with carbamazepine compared with the other three drugs at 18 months of follow up only.

During the course of our trial 25 patients $(10 \%)$ were withdrawn from their randomised drug because of unacceptable side effects. Over half of these were due to phenobarbitone-namely, 13 patients representing $22 \%$ of those randomised to this drug, which was significantly more likely to be withdrawn than phenytoin $(3 \%)$, carbamazepine $(11 \%)$, and sodium valproate $(5 \%)$. Table 3 summarises the side effects; these are well known for each drug. In the VA study ${ }^{11}$ of four drugs the incidence of unacceptable toxicity leading to drug withdrawal was much higher at $20 \%$. For the individual drugs the corresponding figures were primidone $33 \%$, phenobarbitone $19 \%$, phenytoin $16 \%$, and carbamazepine $12 \%$. Thus primidone was the major contributor to such toxicity and phenobarbitone was slightly worse than the other two drugs, although not to the degree found in our study. It seems likely that the much higher incidence of side effects overall and for the individual drugs in the VA study than in our study was related to the policy of the VA group to achieve therapeutic plasma drug concentrations soon after 
Table 7 Randomised comparative monotherapy trials in newly diagnosed epilepsy

\begin{tabular}{|c|c|c|c|c|c|}
\hline Authors & No & Seizure type & Drugs & $\begin{array}{l}\text { Follow up } \\
\text { (months) }\end{array}$ & Measures of efficacy \\
\hline $\begin{array}{l}\text { Ramsay et } a^{7} \\
\text { Wilder et al } \\
\text { Turnbull et al }\end{array}$ & $\begin{array}{r}70 \\
61 \\
140\end{array}$ & $\begin{array}{l}\text { TC, } \mathbf{P} \\
\text { TC, T, C } \\
\text { TC, } \mathbf{P}\end{array}$ & $\begin{array}{l}\text { PHY CBZ } \\
\text { PHY SV } \\
\text { PHY SV }\end{array}$ & $\begin{array}{l}6 \\
6 \\
24\end{array}$ & \multirow{3}{*}{$\begin{array}{l}\text { Complete control } \\
\text { Complete control during months } 2-6 \\
\text { Time to 1st seizure. } \\
\text { Time to } 2 \text { year remission } \\
\text { Seizure frequencies } \\
\text { (excellent, good, poor) } \\
\text { Seizure frequencies. } \\
\text { Total number of seizures. } \\
\text { First seizure recurrence. } \\
\text { Total seizure control. Seizure rating } \\
\text { scale (severity and quality of life) }\end{array}$} \\
\hline Callaghan et al ${ }^{10}$ & 181 & TC, $P$ & $\begin{array}{l}\text { PHY CBZ } \\
\text { SV }\end{array}$ & $14-24$ & \\
\hline Mattson et al ${ }^{11}$ & 421 & $P \pm T C$ & $\begin{array}{l}\text { PHY CBZ } \\
\text { PB PRM }\end{array}$ & 36 & \\
\hline
\end{tabular}

the onset of treatment and to increase drug dosage even higher in the event of continuing seizures. The intolerable side effects leading to withdrawal in both our own and the VA study are of an acute, subacute, or idiosyncratic kind and do not consider the issue of more subtle chronic side effects, especially of the cognitive type, which may not be severe enough to lead to drug withdrawal but which may also influence the choice of drug. ${ }^{16} 17$

Our study has confirmed not only that there are no major differences in efficacy between the four randomised drugs for newly diagnosed tonic-clonic or partial seizures with or without secondary generalisation, but that overall the prognosis associated with each of the drugs was good. Thus by three years of follow up nearly one third of our patients have remained seizure free from the onset of treatment and three quarters of patients had entered one year of remission. A similar prognosis was noted for the four drugs in the VA study and in the two drug study by Turnbull et $a l,{ }^{9}$ as had earlier been described by Elwes $e t$ $a l^{3}$ in the first prospective but non-randomised study of phenytoin and carbamazepine monotherapy in newly diagnosed epilepsy. Similar conclusions may perhaps be inferred from the other three studies summarised in table 7 , but direct comparisons cannot be made because of the short duration of follow up $^{78}$ or different methods of analysis. ${ }^{10}$

It should be stressed that none of the studies, including our own, consider the question of the efficacy of the drugs concerned, which would have required placebo controlled trials, but only the comparative efficacy of each of the drugs in relation to others also utilised as monotherapy. The efficacy of the drugs has been established in placebo controlled trials on patients with chronic epilepsy ${ }^{18}$ but, for ethical reasons, not in newly diagnosed patients. It is widely accepted that evidence of efficacy in chronic patients, a very demanding test of any antiepileptic drug, implies efficacy in newly diagnosed patients, but as the natural history of untreated newly diagnosed epilepsy is uncertain, ${ }^{19}$ the exact contribution of the antiepileptic drugs to the very good prognosis in such patients is also unclear. Blinding of the present study involving four drugs on a long term basis was not a practical option and would also have introduced bias due to a very large drop out rate, as in the VA study. ${ }^{11}$
The findings in this and previously reported comparative efficacy studies apply only to patients with tonic-clonic seizures or partial seizures with or without secondary generalisation, the only seizure types to be studied. They do not relate to other seizure types or to specific epilepsy syndromes. Only one patient developed myoclonus after randomisation and could in retrospect be considered to have had juvenile myoclonic epilepsy. Furthermore, the patients in our own and previous studies have been randomised on the basis of clinical evidence and therefore no conclusions can be drawn about the possible implications of EEG findings for comparative antiepileptic response, which would require separate study. It was of interest, however, that when 17 patients with focal EEG abnormalities were switched from the tonic-clonic group to the partial with or without secondary generalisation group the findings with respect to comparative efficacy for the two seizure subgroups were unchanged.

In conclusion, we have found no significant differences in the efficacy of phenobarbitone, phenytoin, carbamazepine, or sodium valproate in newly diagnosed previously untreated adult patients with two or more tonic-clonic or partial seizures with or without secondary generalisation. This is broadly in keeping with the few previously published studies of randomised comparative monotherapy trials, summarised in table 7 , in particular the only other large scale randomised comparison of four drugs by the VA cooperative group. ${ }^{11}$ The VA study did not include sodium valproate but did include primidone. Since the preparation of this report the VA group have recently published a further multicentre comparative trial of carbamazepine against valproate and concluded that although there were no differences in efficacy between the drugs on secondarily generalised seizures, carbamazepine was superior to valproate on some measures of efficacy against complex partial seizures. ${ }^{20}$ There are important differences in trial design and analysis between the VA study and our own ${ }^{21}$ and some of the conclusions of the VA study have been questioned. ${ }^{21-23}$ The present study confirms that the overall outcome with each of the four test drugs was good, in keeping with our own and other previous studies of the prognosis of newly diagnosed epilepsy treated with monotherapy with a standard drug. In view of 
the similar efficacy of the drugs in this patient population, we confirm that the choice of drug for such newly diagnosed patients may be more influenced by considerations of side effects and costs. ${ }^{56}$ With regard to side effects, although the overall incidence of unacceptable toxicity was much lower in our own than in the VA study, for the reasons discussed, phenobarbitone was associated with significantly more toxicity than the other three drugs.

The study was approved by the ethics committees of King's College and Walton Hospitals. We are grateful to the steering committee of the Medical Research Council, who monitored this study and to the Medical Research Council, who supported it. We also thank The Health Promotion Trust, CibaGeigy, Warner Lambert, and Sanofi. We are grateful to Malcolm Laundy and Louis Vydelingum for the antiepileptic drug monitoring.

1 Shorvon SD, Reynolds EH. Unnecessary polypharmacy for epilepsy. BMF 1977;1:1635-7.

2 Reynolds EH, Shorvon SD. Monotherapy or polytherapy for epilepsy? Epilepsia 1981;22:1-10.

3 Elwes RDC, Johnson AL, Shorvon SD, Reynolds EH. The prognosis for seizure control in newly diagnosed epilepsy. $N$ Engl f Med 1984;311:944-7.

4 Shorvon SD. The temporal aspects of prognosis in epilepsy. If Neurol Neurosurg Psychiatry 1984;47: $1157-65$.

5 Reynolds EH. Early treatment and prognosis of epilepsy. Epilepsia 1987;28:97-106.

6 Chadwick D, Turnbull DM. The comparative efficacy of antiepileptic drugs for partial and tonic clonic seizures. antiepileptic drugs for partial and tonic clonic
f Neurol Neurosurg Psychiatry 1985;48:1073-7.

7 Ramsay RE, Wilder BJ, Berger JR, Bruni J. A double-blind study comparing carbamazepine with phenytoin as initial seizure therapy in adults. Neurology 1983;33:904-10.
8 Wilder BJ, Ramsay RE, Murphy JV, Karas BJ, Marquardt $K$, Hammond EJ. Comparison of valproic acid and phenytoin in newly diagnosed tonic-clonic seizures. Neurology 1983;33:1474-6.

9 Turnbull DM, Howell D, Rawlins MD, Chadwick DW. Which drug for the adult epileptic patient: phenytoin or valproate? $B M \mathcal{F} 1985 ; 290: 8150-9$.

10 Callaghan N, Kenny RA, O'Neill B, Crowley M, Goggin T. A prospective study between carbamazepine, phenyT. A prospective study between carbamazepine, phenytoin and sodium valproate as monotherapy in previously untreated and recently diagnosed patients with

11 Mattson RH, Cramer JA, Collins JF, et al. Comparison of carbamazepine, phenobarbital, phenytoin, and primidone in partial and secondarily generalized tonic-clonic seizures. $N$ Engl $\mathcal{F}$ Med 1985;313:145-5

12 De Silva M, McArdle B, McGowan M, Neville BGR, Johnson AL, Reynolds EH. Monotherapy for newly diagnosed childhood epilepsy: a comparative trial and prognostic evaluation. Epilepsia 1989;30:662.

13 Peto R, Pike MC, Armitage P, et al. Design and analysis of randomised clinical trials requiring prolonged observation of each patient. I. Introduction and design. II. Analysis and examples. $\mathrm{Br} \mathcal{F}$ Cancer 1976;34:585-612; 1977;35:1-39.

14 Hosmer DW, Lemeshow S. Applied logistic regression. New York: Wiley, 1989.

15 Machin D, Campbell MJ. Statistical tables for the design of clinical trials. Oxford: Blackwell, 1987.

16 Reynolds EH. Chronic antiepileptic toxicity: a review. Epilepsia 1975;16:319-52.

17 Reynolds EH. Mental effects of antiepileptic medication. A review. Epilepsia 1983;24 (suppl 2):85-95.

18 Gram L, Bentsen KD, Parnas J, Flachs H. Controlled trials in epilepsy: a review. Epilepsia 1982;23:491-519.

19 Elwes RDC, Johnson AL, Reynolds EH. The course of untreated epilepsy. $B M \Im$ 1988;297:948-50.

20 Mattson RH, Cramer JA, Collins JF, et al. A comparison of valproate with carbamazepine for the treatment of complex partial seizures and secondarily generalised tonic-clonic seizures in adults. $N$ Engl 7 Med 1992; 327:765-71.

21 Reynolds EH, Heller AJ, Chadwick D. Valproate versus carbamazepine for seizures. $N$ Engl f Med 1992;328: 207-8.

22 Johnson AL. Valproate versus carbamazepine for seizures. NEngl f Med 1993;328:208.

23 Hernandez-Vidal A. Valproate versus carbamazepine for seizures. N Engl f Med 1993;328:207-8. 